\title{
Analysis and Research on Specialty Packaging Design under Central Plain Culture
}

\author{
Zhenpeng Zhao \\ College of Art and Design \\ Huanghe Science and Technology University \\ Zhengzhou, China 450006
}

\begin{abstract}
The land of China is rich in natural resources with each region having a variety of local specialties. Taking the specialties of Henan, which is located in the Central Plains, as an example, they are really good, but haven't received corresponding market position, and specialty packaging design does not obtain good results in terms of its role in promotion. With the increasingly fierce market competition, Henan specialty will face greater opportunities and challenges. I propose the question about specialty packaging design based on outlining Central Plain Culture and Henan specialty packaging design, to discusses specialty packaging future for the formation of packaging design brand.
\end{abstract}

Keywords-Central Plain; specialty; packaging design

\section{INTRODUCTION}

Packaging and packaging design are the products of economic society when it develops to a certain stage. During the development of society at that time, some new technologies appeared, enabling manufacturing and agricultural producers to provide their products via a packaged form to stores. These technologies enable agricultural producers to transport fresh products to the markets for the first time, and at the same time, enable manufacturers to make their products more pleasing for the merchants to sell.

The development of packaging technology not only reflects the scientific and technological level of a country, but also reflects a nation's cultural spirit and material civilization progress degree. As a dual carrier of ideology culture and economic activity, as a form of expression, packaging design can reflect the geographical and cultural characteristics, which is not only an important means of obtaining economic benefits, but especially in the expression of some traditional honored goods and local characteristic commodities, it is a good design strategy. From packaging design forms, specialty packaging is the reflection of modeling archaizing and folk natural materials combination, striving to show commodities' cultural characteristics with distinct geographical and cultural image characteristics. Thus, specialty packaging design has a function of displaying commodities' cultural value directly and indirectly.

Packaging is the important part of product planning, propaganda, marketing strategy, and establishment of corporate image, and packaging design is the soul of packaging industry development, and the bridge linking design art and modern technology and the market. The design schemes directly influence packaging production and processing, way of consumption, quality performance and commodity market economic effect. The overall design level of a country or region concerns packaging development and future. The difficulty of packaging design lies not only in its complex subordination and commodity, but also lies in whether it can absorb and utilize the advanced achievements of modern science and technology as well as culture and arts to improve development and create the new packaging that lead market and consumption trend comprehensively.

\section{HenAn PaCKAging Design Under Central Plain CULTURE}

The land of China is rich in natural resources, having a long history, with each region having a variety of local specialties. China is a country with vast territory and long history, which naturally produces all sorts of local culture. Local specialties stem from the folk society. Most of them are the results cultivated by the public from different regions having different national customs, which have combined a lot of wisdom, hard work and sweat, accumulated a long history and culture, showing the strong geographical and cultural characteristics. The specialty of each region has the cultural imprint of their region. Therefore, specialty packaging shall also echo with the local regional culture, to make out the beautiful design meeting people's aesthetics.

Central Plains is one of the main birthplaces of the Chinese nation, having good products from earth and natural treasures, great people and outstanding land, with talents and hero coming forth in large numbers. Central Plain is rich in resources with long history, and has a rich and colorful culture and art. There is a saying for thousands of years that "he who obtains Central Plain obtains the world". In the Neolithic Age four thousand years ago, people of the Central Plain created the famous "Peiligang Culture", "Yangshao Culture" and "Longshan Culture." Long history also makes this land diverse in specialty, such as Lushan Silk, Lankao lily, Nanyang jade carving, folk paper-cut in western Henan, Henan jujube, Ruyang plum jade and so on. All of them reflect the local historical and cultural characteristics, providing consumers with good gifts, but also provide the visitors with good souvenirs. 
China has eight ancient capitals, and there are three in Henan, so one can imagine its arts and culture deposition. The reason of Central Plain's profound culture and art is not merely the social and historical factors, but also is deeply influenced by its geographical location. Because it locates at the central of China, so its forms of art also absorb the advantages of others, integrating the magnificent Beijing and Tianjin, the pretty Suzhou and Yangzhou, delicate Guangdong and Fujian as well as the rough Yunnan and Burma, having its own unique charm and wide range of art and culture charm. Art is the culture left after elimination by time. Some traditional specialty packaging of Central Plain can be spread up to now after many years' screening, so its regional cultural accumulation is evident. "Each place has its own way of supporting its own inhabitants", which is also correct the other way round, namely "the inhabitants can also transform one place." The cultural characteristics of one specialty packaging are certainly closely related to this region's cultural environment, local customs, religious beliefs and living habits.

Taking Henan specialties as an example, they are really good, but haven't obtained corresponding market position. There are many reasons, and the important one is that specialty packaging design hasn't obtained good results in terms of its role in promotion of products. These local specialties not only have high artistic value and popularity, and with the deepening of reform and opening up, the local specialties of various places have also become the main force driving local economy. Therefore, how to give full play to local products to serve its economy and promote local economic growth, is a problem to be solved faced by people. With the increasingly fierce market competition, Henan specialty will face greater opportunities and challenges. It will have a positive effect on Henan specialty's deep development and market expansion if strengthen packaging art's design and research based on continuing to improve specialty quality.

\section{Problems of Henan Specialty PaCKaging Design}

\section{A. Simple Packaging Form and low Added Value}

With the deepening of reform and opening up, the local specialties of various regions have also become the main force driving local economy. Henan local specialty packaging design does not make too many changes due to the development of such trend. Packaging is an effective means to enhance brand image. Although product quality comes first, rough packaging will make people doubt about the quality of the brand. For example, the simple packaging form reflects in the selection of packaging materials and unsuitable product characteristics; inappropriate selection and match of packaging color, graphics, text and material; unable to represent the unique custom and folk culture in Central Plain and so on. In addition, the abundant quality watermelon, kiwi and apple in Henan are mostly sold via simple packaging or scattered packaging. Therefore, such kind of commodity often has low added value.

\section{B. Excessive Packaging and Overlooking Their Own Values}

As an important part of commodities circulation, reasonable and novel packaging has played a role in promoting commodity production and marketing. In recent years, many commodity producers gradually start to pay attention to product packaging and have spent a lot of financial, material and manpower resource on packaging. However, with manufactures' increasing emphasis on the concept of packaging, the errors such as excessive packaging and imitate packaging in terms of packaging design have also emerged. Enterprises believe that gorgeous and fancy packaging appearance can play a good role in promoting commodity sales, so they no longer care about the development of new products and enhancement of product quality, ignoring long-term planning in terms of packaging design positioning. Such behavior of being anxious to achieve quick success and get instant benefits can only attract temporary trust from a small part of consumers' with immature consuming psychology. It is an undesirable behavior in the long run.

\section{Large Proportion of Simulating and Learning, Lacking of Innovation}

The entry threshold of local specialty marketing industry is not high, the operator of specialties have uneven knowledge level and cultural qualities, and many commodity producers are short of awareness of independent innovation, so the imitation packaging without personality is particularly prominent. With the development of the times, people continue to explore and find some interesting content and aesthetic tastes in local specialty packaging design, a kind of concern and experience of local traditional culture, the pursuit and exploration of artistic taste, which has become a higher pursuit beyond specialty consumption. Therefore, many consumers prefer distinctive and innovative packaging products. Some enterprises try to make simple imitation of some famous-brand products for more profits within short time, and their products are similar to those from color to text and from the material to shape. Such packaging design positioning of imitation is difficult to be recognized by consumer psychology, and even is suspected to be infringement.

\section{Future of Henan Specialty Packaging Design}

\section{A. Conduct Positioning Based on Consumers' Needs}

Consumers always pay attention to the value and effectiveness of commodities. Price can be a direct reflection of the quality level of the products. While considering packaging design based on product price, packaging designers shall learn how to package appropriately. Some consumers buy commodities to use on the one hand, and on the other hand, they want to show their status, education and appreciation, etc., to pursue the psychological value of consumer goods. Consumers are purposeful and targeted while buying commodities, we should conduct packaging design based on consumers' specific needs. For example, list the product's nutrient content, methods of preparation, precautions and the production date in detail using tables and graphs, further reflect enterprises' responsible attitude toward consumers with such standardized and specialized services, and this attitude can be said as the best respect for the consumers, therefore, consumer's long term trust on this brand will be obtained. 


\section{B. Improve Product Quality}

Packaging design is just one of the means in assisting sales between product packaging and the product itself, yet product's inherent quality is the most fundamental and most critical. If the product only has beautiful package but with poor quality, consumers will doubt on the product quality and credibility after purchasing and using, thus result in discontent or even disgust, and it is difficult for them to have the desire of buying again, or even point out directly of this product's fraudulent behavior during communication with other consumers. As a result, it will certainly lose the market once a bad reputation is established in more and more consumers' mind.

\section{Create Packaging Design Brand for Local Specialties}

The cultural connotation of brand is to enhance the value of brand itself and the motive power of product market competition. In the entire brand marketing system, packaging design shall face the consumers directly as a terminal tool, to make one to one communication with the consumers directly, namely, brand recognizes consumers, advertisement attracts consumers, and packaging design impresses consumers. So we can say that packaging design is the ultimate interpreter of brand culture. Visual impact is unpredictable. With the deepening of market economic reforms and the aggravation of market competition, merchants have fully realized the important meaning of packaging design to attract consumers' "first impression", particularly the local specialties, although they have profound historical culture and featured local conditions and customs, they start quite late compared to modern commodity manufacturing in terms of brand building, having been lagged behind. If still not pay attention to the importance of packaging design in attracting consumers, it is difficult to gain a foothold in the fierce market, at the same time, it is a waste of resources. Designers shall combine the profound culture and long history of Henan, to enhance advantage and avoid disadvantage for local specialty packaging design, and fully reflect the local characteristics, cultural characteristics and historical features, so that more people will love and accept it through a more rational, more effective and more attractive specialty packaging, thus to create their own local specialty packaging design brand.

\section{CONCLUSION}

Packaging design is part of the visible cultural features among business activities. The whole business activity involves many cultural levels. With human's entering into the 21 st century, commodity economy has experienced unprecedented prosperity, and the consumer market as well as consumer attitudes have undergone tremendous changes. The specialties have their own unique geographical advantage and cultural connotation. For many years, the products couldn't be sold at good prices, and the specialties have nothing special. Due to producers' one-sided understanding toward packaging design, coupled with the low-end price, the manufacturers no longer want to improve product quality. It will lose the specialty if the specialty's quality is lost, rendering increasing limitations to the specialty's brand and popularity.
Specialty packaging is a miniature of the image of a country or a region. Therefore, as for the research on specialty packaging design, designers are required to make unremitting exploration to discover some unique content and a higher aesthetic taste from the packaging. Specialty packaging should reflect local characteristics, namely, to reflect regional culture characteristics with boutique packaging awareness and cultural connotation. While designing, attention shall be paid to convenience, shall maintain an attention and deepening experience toward the traditional culture and national style, as well as a green pursue of nature, health and environmental protection. The improvement of specialty packaging design level is conducive to reflect cultural connotation of specialty, and reflects the national culture, scientific and technological strength and ideological level of a region invisibly.

Henan is located in the Central Plains, having a long history and profound characteristic local specialties. If strengthen packaging design and research continuously based on specialty quality improvement, it will play a positive role in developing Henan local specialties in depth and market expansion. Starting from packaging design research is a very effective way, which not only can reflect the true market value of local specialty, but also can drive the local economy development, thus to improve people's income, and serve the local economy, to ultimately realize the double harvest of local specialty's social benefits and economic benefits.

\section{REFERENCES}

[1] Ma Ye. Local Specialty and Packaging. [J]. Art Education, 2013, 03: 160-161.

[2] Wang Lin. Research on Application of Regional Culture in Packaging Design of Central Plain Specialties [D].Jiangnan University, 2007.

[3] Zeng Dilai. Modern Packaging Design [M].Changsha: Central South University Press, 2005.

[4] Pan A'fang. Discussion on Regional Design of Local Specialty Packaging [J]. Beauty \& Times (Second Half), 2008 (12).

[5] Yuan Enpei. Application and Research of Consumer Psychology in Packaging Design [J]. Packaging Engineering, 2004, 25 (1): 105-107.

[6] Connella - Robin - Landa. Tricks of Graphic Design [M]. Shanghai: Shanghai People's Fine Arts Publishing House, 2006.

[7] Xiong Limei, Zhu Zonghua. Packaging Design of Specialty Commodities [J]. Packaging Engineering, 2009, 06: 173-174. 